\title{
Fatness and thermoregulation of qualified rugby players
}

\author{
Inese Pontaga ${ }^{1, *}$, Jekaterina Liepina ${ }^{1}$, Dzintra Kazoka $^{2}$, and Silvija Umbrasko ${ }^{2}$ \\ ${ }^{1}$ Latvian Academy of Sports Education, Riga, Latvia \\ ${ }^{2}$ Rīga Stradinš̌ University, Department of Morphology, Riga, Latvia
}

\begin{abstract}
A large body size and mass are advantages in rugby. The desire to gain weight can bring players to become overweight or obese. This can worsen their thermoregulation and health risks. The aim was to evaluate anthropometric characteristics and to determine the effect of additional body fat percentage on sweat loss during play-match in male rugby players. Nineteen qualified male rugby players were tested during play-match. The age, height, body mass, body mass index (BMI) and body fat percent of participants were: $29 \pm 6$ years, $183 \pm 7 \mathrm{~cm}, 96.86 \pm 12.88 \mathrm{~kg}$, $29.07 \pm 3.90 \mathrm{~kg} / \mathrm{m}^{2}, 20.52 \pm 5.64 \%$, respectively. The skin fold thickness measurement was used to assess body fat percent. Body mass loss was detected by weighting. The mean BMI was $26.18 \pm 2.37\left(\mathrm{~kg} / \mathrm{m}^{2}\right)$ and the body fat $15.87 \pm 3.97 \%$ in backs. Forwards were significantly heavier and had BMI $31.18 \pm 3.44\left(\mathrm{~kg} / \mathrm{m}^{2}\right)(p=0.002)$ and the body fat $23.91 \pm 4.02 \%(p<0.001)$. The mean body mass decrease in the playmatch was $1.83 \pm 0.84 \%$. The mean sweating intensity was $2.24 \pm 1.071 / \mathrm{h}$, but individual varied among players in very wide range $(1.12-6.161 / \mathrm{h})$. Relationships between the body fat percentage and sweating intensity was not determined $(p>0.05)$. Recommendation is to increase the volume of regular strength training, to correct the diet and liquid consumption.
\end{abstract}

Key words: overweight, dehydration, performance, health risks prevention, sport.

\section{Introduction}

Physical activity promotion and participation in organised sports is an important recommendation in the prevention and treatment of obesity, metabolic and cardiovascular risks reduction, health and fitness improvement [1]. Obesity is a complex, multi-factorial, and largely preventable disease, affecting, along with overweight, over a third of the world's population today [2,3]. Investigation conducted by Kelly et al. [4] is in a good agreement with these data, they evaluated that $23.2 \%$ of the world's adult population in 2005 was overweight and $9.8 \%$ was obese. If the trends of body fatness increase continue, by 2030 an estimated $38 \%$ of the world's adult population will be overweight and $20 \%$ will be obese [4]. Therefore, increase of daily physical activity duration and participation in sports training must improve the body mass composition and health in population. However, sports participation not always improve the body mass composition in athletes. A large body size and mass is an advantage in some contact sports games (rugby, American football, team

\footnotetext{
* Corresponding author: inese.pontaga@lspa. $1 \mathrm{v}$
}

(C) The Authors, published by EDP Sciences. This is an Open Access article distributed under the terms of the Creative Commons Attribution License 4.0 (http://creativecommons.org/licenses/by/4.0/). 
handball), especially in some positions' players. For example, Hill et al. [5] determined that international level rugby players' body mass has significantly increased since 1995: in 1955 the mean rugby players' body mass was $84.8 \pm 8.2 \mathrm{~kg}$ but in 2015 , it was $105.4 \pm 12.1 \mathrm{~kg}$, an increase of 24.3\%. Between 1955 and 2015, the body mass of forwards increased steadily, whereas that of backs has mostly gone up since 1995. Large body size and mass can be achieved by increase of skeletal muscle mass due to resistance training, which is beneficially. Unfortunately, sometimes fatness of athletes occurs because high body mass is achieved by increase in body fat content. So, Malina et al. [6] observed a high prevalence of overweight and obesity (42.6\%) among young American football players.

The Body Mass Index (BMI) is a commonly used measure of fatness by which individuals may be classified as lean (norm), overweight or obese. The BMI is calculated using the following Eq. (1):

$$
B M I\left(k g / m^{2}\right)=\text { body mass }(\mathrm{kg}) / h e i g h t^{2}\left(\mathrm{~m}^{2}\right)
$$

Individuals with a BMI of $25.0-29.9 \mathrm{~kg} / \mathrm{m}^{2}$ are classified as overweight, whilst those with BMI $>30.0 \mathrm{~kg} / \mathrm{m}^{2}$ are classified as obese $[7,8]$.

Heo et al. [9] developed cut-offs of percentage of body fat on the basis of the relation between dual-energy X-ray absorptiometry-measured fat mass and BMI (in $\mathrm{kg} / \mathrm{m}^{2}$ ) stratified by sex, age, and race-ethnicity by using 1999-2004 NHANES data. They determined that in males, the body fat percentage corresponded to a BMI of 18.5, 25, 30, 35, and 40 across age and racial-ethnic groups ranged from $12.2 \%$ to $19.0 \%, 22.6 \%$ to $28.0 \%, 27.5 \%$ to $32.3 \%$, $31.0 \%$ to $35.3 \%$, and $33.6 \%$ to $37.6 \%$, respectively.

High value of the body mass index (BMI) can be estimated as overweight in athletes with great skeletal muscles mass. This means that the reason of high BMI can be hypertrophy of skeletal muscles in athletes training in many sports specializations [10]. For example, BMI $\left(25.1 \pm 2.9 \mathrm{~kg} / \mathrm{m}^{2}\right)$ is high in young Latvian handball players from Murjani Sports Gymnasium, but this is due to high lean body mass because the body fat percentage $(13.6 \pm 2.8 \%)$ is in norm in young male handball players [11]. The mean BMI $\left(23.4 \pm 1.4 \mathrm{~kg} / \mathrm{m}^{2}\right)$ is lower and its value coincides with norm is Latvian qualified football players but the mean body fat percentage is greater $(18.4 \pm 3.7 \%)$ in comparison with the handball players [11]. Therefore, fitness rather than fatness has been proposed as the main marker of health. One rugby player can be overweight according the BMI without being fat and other athlete can also be overweight and fit [12].

The desire to gain weight can bring rugby players to become overweight or obese. This could worsen their thermoregulation and increase health risks in future. Therefore, the aim of the present study was to evaluate anthropometric characteristics and to determine the effect of additional body fat percent to sweat loss during play-match in qualified male rugby players.

\section{Material and methods}

\subsection{Participants}

Nineteen male rugby 15 players from the Latvian National team were tested during a play-match. They voluntary participated in our study (every athlete signed an informed consent form to take part in the investigation). The study was performed in accordance with the standards of the Ethics Committee of Latvian Academy of Sports Education and in accordance with the Declaration of Helsinki. The mean age of the participants was $29 \pm 6$ years. Their training experience in rugby 15 ranged from seven to fifteen years. These 
athletes trained four times per week (one and half to two hours per day) and played regularly on the weekends (the mean: $8.2 \pm 3.4$ training or playing hours per week).

\subsection{Methods}

The players' height was measured using an Ultrasound Height Measuring Unit MZ10020 (ADE, Hamburg). Body mass was measured in athletes wearing briefs using of special industrial scales Midrics1 (Sartorius, Germany) with precision of 0.01 kilogram. The body mass index (BMI) was calculated by using Eq. (1) [7, 8].

The mean anthropometric characteristics of all athletes and each position players (forwards and backs) separately were analysed. The method of skin fold thickness measurement in seven sites by Jackson/ Pollock with a calliper SH5020 (SAEHAN Ltd., Korea) was used to assess percentage of body fat (\% BF) by equation for males (2) [13]:

$$
B F(\%)=495 /[1.112-(0.00043499 \cdot s)+(0.00000055 \cdot s \cdot s)-(0.00028826 \cdot a)]-450
$$

Where: $\mathrm{s}=$ sum of seven skin fold $(\mathrm{mm}) ; \mathrm{a}=$ age (years).

Weighting of every athlete wearing only briefs was repeated immediately after play-match using the same industrial scales Midrics1 (Sartorius, Germany). Body mass loss of every player was detected by calculating of the body mass difference of every player before and after the play-match.

Measurements were performed at October 1st, 2016 during the play-match with the Lithuanian Premium league team "Ažuolas". The air temperature was $+13^{\circ} \mathrm{C}$ and humidity 69\%. The game took place at the Riga Technical College Sports Stadium. Duration of the play-match was 80 minutes ( 2 x 40 minutes). Time spent in the field by every player was measured. We asked the participants to consume the fluid as they usually do according to their subjective thirst sensation and not change their drinking habits before the play-match and during it. All water bottles of every player were weighed before and after training by using of industrial scales Midrics1 (Sartorius, Germany). The urine produced by athletes during the break and after the play-match was weighed with the same scales. Sweating intensity of every rugby players was calculated from the data of the body mass changes, consumed water mass, produced urine mass and the duration of playing on the field in this play-match, taking into account that $1 \mathrm{~kg}$ of water $=1$ litre of water (3) [14]:

$$
\begin{aligned}
& \text { Sweat rate }(l / h)=\{[\text { pre }- \text { practice mass }(k g)-\text { post practice mass }(k g)]- \\
& \text { produced urine mass }(k g)+\text { fluids consumed during practice }(\mathrm{kg})\} \\
& \text { /duration of playing on the field in this play - match }(h)
\end{aligned}
$$

\subsection{Statistical analysis}

The data distribution was evaluated from the values of the skewness and kurtosis and skewness and kurtosis $t$ - test analysis. The data of the athletes' age, height, body mass, body fat percent, body mass loss after play-match were normally distributed. Therefore, using parametric statistics was appropriate. Mean values and standard deviations for all characteristics were calculated. Student's independent t-test for unequal data groups was employed to determine differences between the mean characteristics of the different position players (forwards and backs). The differences were considered significant at $p<0.05$. A correlation between body fat percent and sweating intensity during the play-match was evaluated. Microsoft Excel 2010 was used to perform all statistical procedures. 


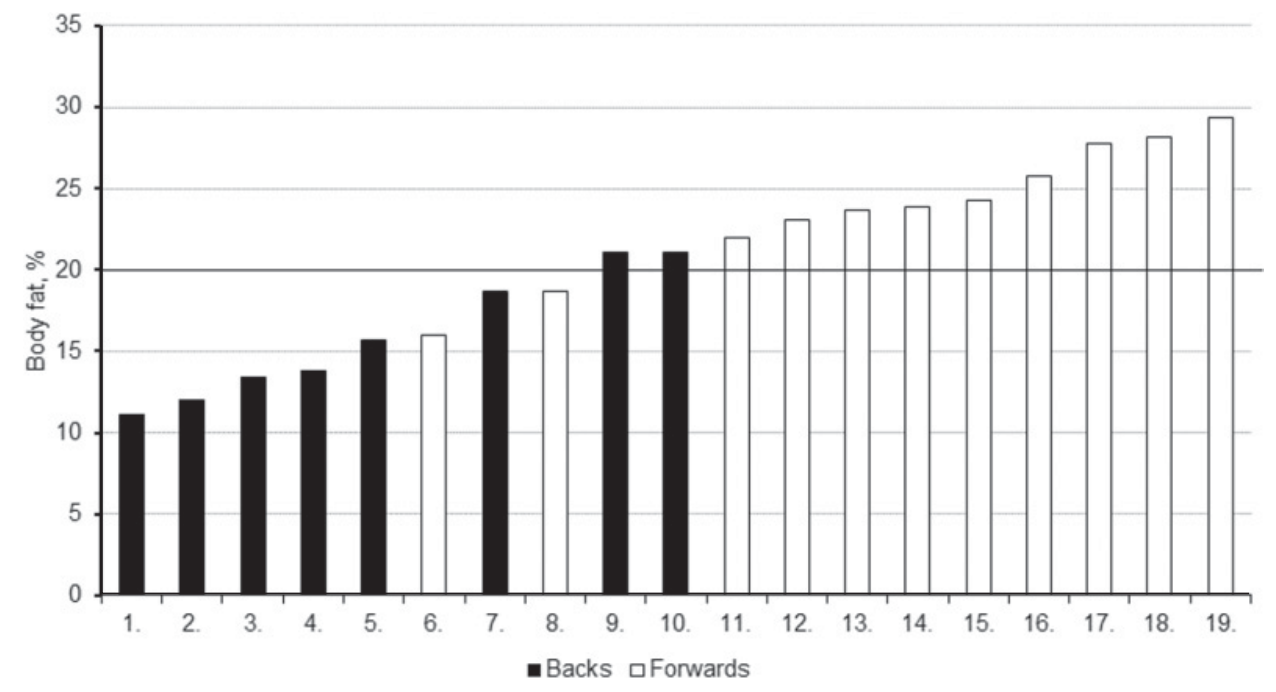

Fig. 1. Body fat percentage in every male rugby player in dependence on his position. Horizontal line at $20 \%$ indicates cut-off value for overweight of the athletes [9].

Table 1. The mean anthropometric characteristics of the rugby athletes in dependence on players' position.

\begin{tabular}{|l|c|c|c|c|}
\hline $\begin{array}{l}\text { Rugby players' } \\
\text { position }\end{array}$ & $\begin{array}{c}\text { Body height, } \\
\mathbf{c m}( \pm \mathbf{S D})\end{array}$ & $\begin{array}{c}\text { Body mass, } \\
\mathbf{k g}( \pm \mathbf{S D})\end{array}$ & $\begin{array}{c}\text { Body mass index, } \\
\mathbf{k g} / \mathbf{m}^{\mathbf{2}}( \pm \mathbf{S D})\end{array}$ & $\begin{array}{c}\text { Body fat, } \\
\mathbf{\%}( \pm \mathbf{S D})\end{array}$ \\
\hline Backs & $180 \pm 6$ & $84.75 \pm 6.38$ & $26.18 \pm 2.37$ & $15.87 \pm 3.97$ \\
\hline Forwards & $184 \pm 7$ & $105.94^{*} \pm 8.62$ & $31.18^{*} \pm 3.44$ & $23.91^{*} \pm 4.02$ \\
\hline $\begin{array}{l}\text { Significance } \\
\text { of difference }\end{array}$ & $p=0.09$ & $p<0.001$ & $p=0.002$ & $p<0.001$ \\
\hline
\end{tabular}

\section{Results}

The mean height, body mass, body mass index (BMI) and body fat percent of all participants were: $183 \pm 7(\mathrm{~cm}), 96.86 \pm 12.88(\mathrm{~kg}), 29.07 \pm 3.90\left(\mathrm{~kg} / \mathrm{m}^{2}\right)$ and $20.52 \pm 5.64$ (\%), respectively. The mean BMI gives evidence about overweight (between 25 and $30 \mathrm{~kg} / \mathrm{m}^{2}$ ) in the players. The mean body fat percentage also is greater than the norm - above $19 \%$. The body fat above $20 \%$ - overweight is observed in 11 players (nine forwards and two backs) from 19 (Fig. 1), but the first step of obesity in three forwards with body fat $27.8 \%, 28.2 \%$ and $29.4 \%$, respectively (the borders from 27.5 to $32.3 \%$, according to [9].

Comparison of the mean anthropometric characteristics of the backs and forwards are shown in the Table 1.

The mean height does not differ significantly in different position players, but the body mass, BMI and body fat percent is statistically significantly larger in forwards than in backs (Table 1). The mean BMI slightly exceed the highest value of norm and can be qualified like overweight in backs but their body fat content is in the norm $(<20 \%)$. The mean BMI of forwards (between 30.0 and $34.9 \mathrm{~kg} / \mathrm{m}^{2}$ ) coincides with the first step of obesity, but the body fat percentage: $23.91 \pm 4.02 \%$ proves only overweight of them (22.6 to $28.0 \%$ ). 


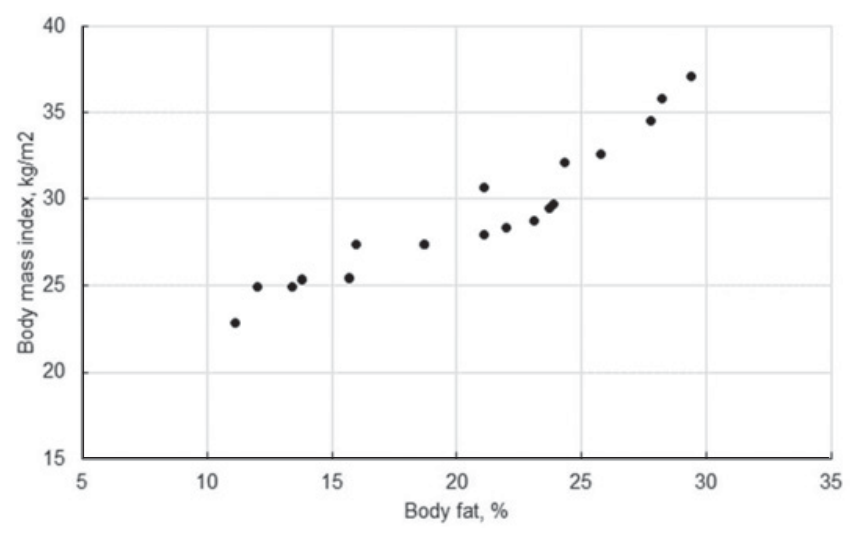

Fig. 2. Relationship between the body fat percentage and BMI in male rugby players $(r=0.94, p=$ $0.001)$.

The close linear positive relationship is determined between the body fat percentage and BMI, equation (4) (correlation coefficient $r=0.94$; probability level $p=0.001$ ):

$$
B M I\left(\mathrm{~kg} / \mathrm{m}^{2}\right)=15.67+0.65 \cdot B F(\%)
$$

This confirms that the reason of high BMI is increased body fat content in our rugby players (Fig. 2).

The time spent by every player in the play-match is $58.74 \pm 23.69$ minutes $(0.98 \pm$ 0.39 hours). The mean water intake during the game is not high: $0.460 \pm 0.334 \mathrm{~kg}$. The mean body mass decrease of the player due to sweating in the play-match is $1.73 \pm 0.71 \mathrm{~kg}$ or $1.83 \pm 0.84 \%$ from the body mass at rest. This is not high and might not affect the performance [15]. Nevertheless, body mass loss exceeds $2 \%$ in six athletes: three backs and three forwards. The body mass decrease is very large (4.36\%) in one back player. Therefore, the performance of these athletes should be worsened (Fig. 3).

The mean sweating intensity of all rugby players is $2.24 \pm 1.07$ litres $(\mathrm{kg}) / \mathrm{h}$. Comparison of the mean body mass changes, sweating intensity, time spent on the field during the playmatch and consumed water intake of the backs and forwards are shown in the Table 2. The playing time spent on the field and consumed amount of water do not differ significantly in backs and forwards (Table 2).

The mean body mass lost by backs is none significantly greater in comparison with the body mass decrease of forwards due to large variation of the weight loss and playing time on the field among different players. The mean sweating intensity does not differ significantly in backs and forwards but individual sweating intensity varies among players in a very wide range: from 1.12 to $3.28 \mathrm{l} / \mathrm{h}$ in the backs and from 1.45 to $6.16 \mathrm{l} / \mathrm{h}$ in forwards.

Significant relationships between the body fat percentage and sweating intensity are not determined in all rugby players $(p=0.54)$, as well as in the back players $(p=0.21)$ and forwards $(p=0.70)$. 
1. 2. 3. 4. 5. 6. 7. 8. 9. 10. 11. 12. 13. 14. 15. 16. 17. 18. 19.

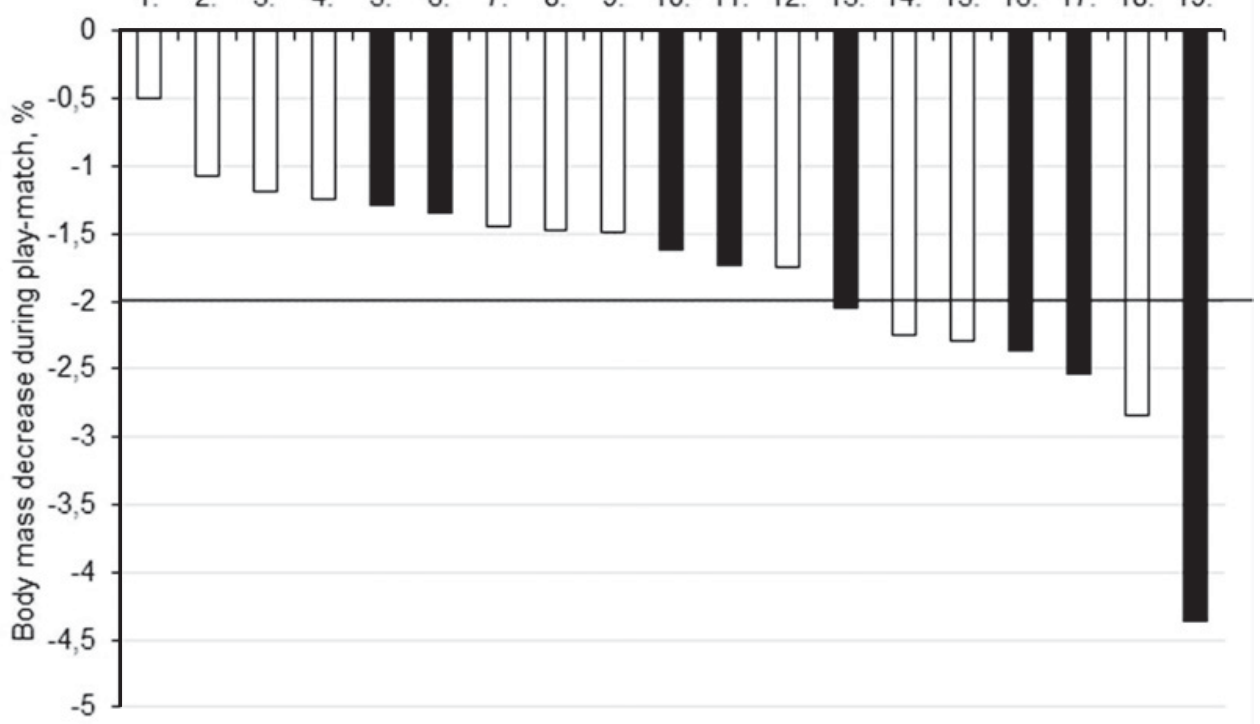

-Backs 口Forwards

Fig. 3. Body mass decrease according to player's position during play-match. Horizontal line at $-2 \%$ indicates cut-off value for decrease in physical performance [15].

Table 2. The mean duration of playing on the field, consumed water, lost body mass and sweating intensity of the male rugby athletes in dependence on players' position.

\begin{tabular}{|l|c|c|c|c|c|}
\hline $\begin{array}{l}\text { Rugby players } \\
\text { position }\end{array}$ & $\begin{array}{c}\text { Time spent on } \\
\text { the field, hours }\end{array}$ & $\begin{array}{c}\text { Consumed } \\
\text { water, kg }\end{array}$ & $\begin{array}{c}\text { Body mass } \\
\text { decrease, kg }\end{array}$ & $\begin{array}{c}\text { Body mass } \\
\text { decrease, \% }\end{array}$ & $\begin{array}{c}\text { Sweating intensity, } \\
\text { litres }(\mathbf{o r} \mathbf{~ k g}) / \mathbf{h}\end{array}$ \\
\hline Backs & $1.14 \pm 0.33$ & $0.53 \pm 0.42$ & $1.82 \pm 0.79$ & $2.16 \pm 1.00$ & $2.15 \pm 0.75$ \\
\hline Forwards & $0.86 \pm 0.41$ & $0.41 \pm 0.26$ & $1.66 \pm 0.68$ & $1.59 \pm 0.66$ & $2.76 \pm 1.27$ \\
\hline $\begin{array}{l}\text { Significance } \\
\text { of difference }\end{array}$ & $p=0.06$ & $p=0.213$ & $p=0.327$ & $p=0.09$ & $p=0.10$ \\
\hline
\end{tabular}

\section{Discussion}

The mean BMI of all players was $29.07 \pm 3.90\left(\mathrm{~kg} / \mathrm{m}^{2}\right)$, which gives evidence about overweight (between 25 and $30 \mathrm{~kg} / \mathrm{m}^{2},[7,8]$ ) in the players, the mean body fat content $-20.52 \pm 5.64 \%$ also is greater than the norm - above $19 \%$ (highest border in males) [9]. The reason of high BMI is increased body fat content in our rugby players which is confirmed by the close linear positive correlation between the BMI and body fat percent ( $r=0.94 ; p=0.001)$. Our data of the BMI in Latvian National male rugby team agree with the mean BMI $29.0 \pm 2.3\left(\mathrm{~kg} / \mathrm{m}^{2}\right)$ of an Australian National Rugby League team male players at 2009 preseason [16]. Our results are in a good agreement with the data of King et al. [12] who evaluated BMI of international professional rugby players from the four teams involved in the semi-finals of the 2003 Rugby Union World Cup. According to the World Health Organisation $[7,8]$ values for BMI, $65 \%$ of the players were classified as overweight and $25 \%$ as obese. 
Gavarry et al. [17] determined high prevalence of fatness in adolescent rugby players aged from nine to 14 years: $32.8 \%$ of young rugby players were considered as overweight and $12.8 \%$ as obese. They concluded that BMI can overestimate an excess of adiposity for an adolescent player having a high fat-free mass classified as obese or overweight: only $53 \%$ of young players classified as obese and overweight by BMI had an excess body fat.

All previous data demonstrate that high BMI is commonplace and a desirable attribute for sport performance in professional rugby players.

The mean BMI was $26.18 \pm 2.37\left(\mathrm{~kg} / \mathrm{m}^{2}\right)$ and the body fat content $15.87 \pm 3.97 \%$ in our back position players. This also gives evidence about overweight (BMI is between 25 and $30 \mathrm{~kg} / \mathrm{m}^{2},[7,8]$, but body fat percent is in norm - below 19\% [9]. The similar results in the back position rugby players from the A-League (the highest level of the local league in Japan, practicing six days per week, three hours per day) are detected by Nirengi et al. [18]: BMI $25.3\left(\mathrm{~kg} / \mathrm{m}^{2}\right)\left(23.4-26.9 \mathrm{~kg} / \mathrm{m}^{2}\right)$ and the body fat content $15.2 \%(10.6-19.7 \%)$.

Our forwards were significantly heavier than backs and had BMI $31.18 \pm 3.44\left(\mathrm{~kg} / \mathrm{m}^{2}\right)$ which coincides with obesity (BMI $>30 \mathrm{~kg} / \mathrm{m}^{2},[7,8]$. The body fat content $23.91 \pm 4.02 \%$ in forwards coincides only with overweight value (22.6 to $28.0 \%$ ) and does not shows obesity according to classification of Heo et al., [9]. This can be explained by large skeletal muscle mass in our forwards. Anthropometric characteristics observed in Japanese forwards: BMI $29.1\left(\mathrm{~kg} / \mathrm{m}^{2}\right)\left(27.3-32.8 \mathrm{~kg} / \mathrm{m}^{2}\right)$ and the body fat content $21.6 \%(16.1-28.5 \%)$ observed by Nirengi et al. [18] also are close to our data.

Bell [19] estimated body mass composition in amateur male rugby players by skin fold thickness measurement method and determined that the mean body fat content was $19.5 \%$ in forwards (the highest border of the norm 19\%, according to classification of Heo et al. [9], and $12.2 \%$ in backs (in norm: 12.2 to $19.0 \%$, according to classification of Heo et al. [9]. Body fat percentage in both: backs and forwards are lower in comparison with our data, but significantly higher in forwards than in backs in both investigations. Morehen et al. [20] has assessed the body composition of elite European Super League rugby players from more than one club using DXA scan technology. They also reported that there are significant differences between players' positions, especially separating the forwards from the other positional groups, who have larger fat percentage in the body $16.3 \pm 4.3 \%$ in comparison with players of other positions with the body fat content $12-14 \%$.

The main characteristics necessary to backs for success are high power, speed and agility. Therefore additional body fat would worsen their performance. Our backs are leaner than forwards. The main task of forwards is the contact fight to get a ball, and therefore they need high strength and strength endurance to achieve success. High body mass and additional fat mass are important to increase of inertia forces in the contact fight and represent the unique positional demands of forwards, who are required to withstand high-speed physical collision on a more regular basis than the other position players [21]. Therefore our forwards have greater BMI and the fat content than backs. The performance worsening due to higher body fat percent in the forwards might be compensated by the fact that they have less game time than the other groups through tactical substitutions [22]. Increased body fat percentage may be a reason of chronic diseases. For example, Nirengi et al. [18] determined that the rugby players, especially those in the forwards position, are at higher risk of developing of nonalcoholic fatty liver disease. This can be explained by consuming of a diet to increase body mass.

The time spent by every player in the play-match is $58.74 \pm 23.69$ minutes $(0.98 \pm$ 0.39 hours), heavier forwards played shorter time on the field but the playing duration highly varied among the players. Therefore, the playing time does not differ significantly between the backs and forwards. The mean water intake during the game is small: $<0.5$ litres. Insufficient fluid intake for athletes training in cold and moderate temperatures can be 
explained by reduced thirst sensation [23]. The data of our present investigation are in good agreement with our previous results obtained in rugby seven players: fluid consumption according to the thirst sensation in cool conditions (the air temperature in that day of March: $+4{ }^{\circ} \mathrm{C}$, humidity $65 \%$ ) was insufficient to prevent the body hydration status worsening and a decrease of the body mass for more than $1.5-2 \%$ in some players but the fluid consumption in warm environment (the air temperature in that day of June: $+19^{\circ} \mathrm{C}$, humidity $35 \%$ ) better allows preventing the body dehydration and keeping the body mass decrease below $1.5 \%$ [24]. The mean body mass decrease of the player due to sweating in the play-match is $1.73 \pm 0.71 \mathrm{~kg}$ or $1.83 \pm 0.84 \%$ from the body mass at rest, this is not high and might not affect the performance because is lower than $2 \%$ [15].

The mean sweating intensity of all rugby players is $2.24 \pm 1.07 \mathrm{l} / \mathrm{h}$. Individual sweating intensity varied among players in a very wide range: from 1.12 to $3.28 \mathrm{l} / \mathrm{h}$ in the backs and from 1.45 to $6.161 / \mathrm{h}$ in forwards. Therefore, significant relationships between the body fat percentage and sweating intensity is not determined $(p<0.05)$. Differences of sweating rate of an individual are determined by activated sweat gland density and sweat output of the activated glands, which are observed between tropical and temperate natives. These differences should be explained by acclimatisation and genetic reasons [25]. This proves that additional attention must be paid to rehydration strategy of some our rugby players with large sweating intensity (more than $31 / \mathrm{h}$ ) and body mass loss for $3-4 \%$ from the rest value [15] to maintain their performance to the end of play-matches.

Jones et al. [26] compared body mass composition in professional and semi-professional rugby players using dual-energy X-ray absorptiometry (DXA) and did not observed significant differences in age, stature or body mass. They detected relatively less soft tissue fat in professional players in comparison with semi-professional $(17.5 \pm 3.7 \%$ and $14.8 \pm 3.6 \%$ in backs; $21.4 \pm 4.3 \%$ and $20.8 \pm 3.8 \%$ in forwards, respectively) and greater trunk lean mass. Jones et al. [26] concluded that to reduce this discrepancy, some semi-professional players should reduce fat mass and increase lean mass, which may be of benefit for the next season and beyond.

Significant anthropometric changes were observed in players across a professional rugby league playing season, including an overall loss of lean body mass and skeletal muscle mass which regain with preseason training [16]. These findings are in agreement with the observations of Duthie et al. [27], who determined substantial individual variation in lean body mass in qualified male rugby players within and between seasons. They confirmed the lean body mass and skin folds thickness measurement is a potentially useful tool for assessing body composition of athletes. Crewther et al. [28] proved that different equal-volume resistance training protocols (full-body or split-body) four - week application improves the strength and slightly also body mass composition by decrease of body fat percent in male rugby union players.

Limitation of the study is investigation of small number of rugby players during only one play-match. Further research is necessary to determine possible relationships among body fat percentage, sweating intensity and body mass decrease during training and play-matches in dependence on rugby player's position and environmental conditions.

\section{Conclusion}

The mean BMI $29.07 \pm 3.90\left(\mathrm{~kg} / \mathrm{m}^{2}\right)$ and body fat of $20.52 \pm 5.64 \%$ of all the National team players prove overweight. The mean BMI $31.18 \pm 3.44 \mathrm{~kg} / \mathrm{m}^{2}$ and body fat $23.91 \pm 4.02 \%$ of 
our forwards are significantly higher than these characteristics in the backs: BMI $26.18 \pm 2.37$ $\left(\mathrm{kg} / \mathrm{m}^{2}\right)$ and body fat $15.87 \pm 3.97 \%, p \leq 0.002$. The first step of obesity is observed in three forwards with body fat $27.8 \%, 28.2 \%$ and $29.4 \%$. Significant relationships between the body fat percent and sweating intensity is not determined $(p>0.05)$ due to individual sweating intensity variation in wide range among the players.

Therefore, large body mass in rugby players would be better achieved by additional regular strength training to gain skeletal muscle mass and decrease the body fat percent.

The athletes should be educated about nutrition and liquid consumption during training to prevent dehydration and performance decrease.

The authors would like to sincerely thank all the rugby players who participated in the study, and their coach who encouraged the athletes to do that.

\section{References}

[1] A.P. Hills, L.B. Andersen, N.M. Byrne, Br. J. Sports Med. 45, 866-87 (2011)

[2] M.N. Fleming, M. Robinson, B. Thomson, et al., Lancet. 384, 766-781 (2014)

[3] G.A. Stevens, G.M. Singh, Y. Lu, G. Danaei G, J.K. Lin, M.M. Finucane, A.N. Bahalim, R.K. McIntire, H.R. Gutierrez, M. Cowan, Ch.J. Paciorek, F. Farzadfar, L. Riley, M. Ezzati, Popul. Health Metr. 10, 22 (2012)

[4] T. Kelly, W. Yang, C.S. Chen, K. Reynolds, J. He, Int. J. Obes. 32, 1431-7 (2008)

[5] N.E. Hill, S. Rilstone, M.J. Stacey, D. Amiras, S. Chew, D. Flatman, N.S. Oliver, BMJ Open Sport Exerc. Med. 4, e000459 (2018)

[6] R.M. Malina, P.J. Morano, M. Barron, S.J. Miller, S.P. Cumming, A.P. Kontos, B.B. Little, J. Pediatr. 151, 378-82 (2007)

[7] World Health Organization. Obesity: preventing and managing the global epidemic: report of a WHO consultation (World Health Organization, Geneva, 2000), pp. 1-253

[8] D. Gallagher, S.B. Heymsfield, M. Heo, S.A. Jebb, P.R. Murgatroyd, Y. Sakamoto, Am. J. Clin. Nutr. 72, 694-701 (2000)

[9] M. Heo, M.S. Faith, A. Pietrobelli, S.B. Heymsfield, Am. J. Clin. Nutr. 95, 594-602 (2012)

[10] J.J. Ode, J.M. Pivarnik, M.J. Reeves, J.L. Knous, Med. Sci. Sports \& Exerc. 39, 403409 (2007)

[11] I. Pontaga, J. Zidens, LASE J. Sport Sci. 2, 33 (2011)

[12] N.A. King, A.P. Hills, J.E. Blundell, Eur. J. Sport Sci. 5, 73-75 (2005)

[13] A.S. Jackson, M.L. Pollock, Br. J. Nutrit. 40, 497-504 (1978)

[14] F.S. Godek, A.R. Bartolozzi, J.J. Godek, Br. J. Sports Med. 39, 205-211 (2005)

[15] S. Shirreffs, Scand. J. Med. Sci. Sports. 20, 90-94 (2010)

[16] E.C. Georgeso, B.K. Weeks, C. McLellan, B.R. Beck, BMJ Open 2, e001400 (2012)

[17] O. Gavarry, G. Lentin, P. Pezery, A. Delextrat, G. Chaumet, A. Boussuges, J. Piscione, Sports Medicine - Open 4, 17 (2018)

[18] S. Nirengi, M. Fujibayashi, S. Furuno, A. Uchibe, Y. Kawase, S. Sukino, Y. Kawaguchi, S. Minato, K. Kotani, N. Sakane, Frontiers in Endocrinology. 9, 341 (2018)

[19] W. Bell, Br. J. Sports Med. 13, 19-23 (1979)

[20] J.C. Morehen, H.E. Routledge, C. Twist, J.P. Morton, G.L. Close, Eur. J. Sport Sci. 15, 523-529 (2015)

[21] C. Twist, M. Waldron, J. Highton, D. Burt, M. Daniels, J. Sports Sci. 30, 359-367 (2012) 
[22] C. Twist, J. Highton M. Waldron, E. Edwards, D. Austin, T.J. Gabbett, Int. J. Sports Physiol. Perform. 9, 925-930 (2014)

[23] R.W. Kenefick, M.P. Hazzard, N.V. Mahood, Med. Sci. Sports Exerc. 10, 1528-1534 (2004)

[24] I. Pontaga, L. Voitkeviča, J. Liepina, Proceedings of the 1st World Congress on Health and Martial Arts in Interdisciplinary Approach (Archives of Budo, Warsaw, 2015), pp. 155-164

[25] J. Lee, Y. Shin, Auton. Neurosci. 205, 67-71 (2017)

[26] B. Jones, K. Till, M. Barlow, M. Lees, J.P. O’Hara, K. Hind, PLOS ONE 10, e0133188 (2015)

[27] G.M. Duthie, D.B. Pyne, W.G. Hopkins, S. Livingstone, S.L. Hooper, Br. J. Sports Med. 40, 202-207 (2006)

[28] B.T. Crewther, T.O.L. Heke, J.W.L. Keogh, Biol. Sport. 33, 111-116 (2016) 